\title{
“Being Grounded in the Ancestors and Looking Forward..."-Blending Culturally Competent Research with Indigenous Leadership Styles ${ }^{1}$
}

\author{
Joseph E. Trimble ${ }^{1}$ (D) \\ Published online: 22 October 2019 \\ (C) Society for Prevention Research 2019
}

\begin{abstract}
The themes and topics found in this Prevention Science supplemental issue on Promoting Health Equity through Rigorous, Culturally Informed Intervention Science: Innovations with Indigenous Populations in the United States represent a comprehensive array of essential considerations for the ethical and principled conduct of health-related research with indigenous communities. The topics are inclusive of what must be considered when researchers realize "culture matters" in the conduct of ethnocultural field-based research. The reader is introduced to profound insights, engaging observations, important research results, and cutting-edge commentary on the future of health-centered research and practice with indigenous populations. In reflecting on the general intent of the issue, two additional themes are considered. Attention is given to the research relationship and requirements for a significant degree and depth in the cultural competence and sensitivity of field-based research teams. Consideration also is given culture and leadership style at the local community level in research programs. These twin considerations have bearing on two important questions facing future research in Indigenous health. In effect, who will guide the community's policies, practices, and experiences of the research teams? Who will lead the funding and policy sources and the next generation of researchers?
\end{abstract}

In the late twentieth century, Joseph Eagle Elk (1931-1991), a traditional Lakota spiritual leader and holy man, is believed to have said, "We have seen that if you wish to achieve anything of value it is not enough for you to depend upon yourself." The conceptualization, organization, preparation, and writing of this Prevention Science supplemental issue on Promoting Health Equity through Rigorous, Culturally Informed Intervention Science: Innovations with Indigenous Populations in the United States relied on the commitment, cooperation, and dedication of close to 50 indigenous community members and researchers from a variety of academic disciplines. All are members of research teams funded under the NIH multi-institute Intervention Research in Native

I wish to extend my deepest gratitude and admiration for the assistance provided me by my dear friend and colleague, James Allen, Professor, Department of Family Medicine and BioBehavioral Health, University of Minnesota Medical School, Duluth.

Joseph E. Trimble trimble@wwu.edu

1 Department of Psychology, Western Washington University, 516 High Street, Bellingham, WA 98225, USA
American Health (IRINAH) program, actively conducting the research studies described through this issue.

The list of contributors is impressive. They represent a cross-section from young grassroots community leaders to respected elders, and from early career investigators to senior level researchers. I want to use this special occasion to express my profound complements to those kindred spirits, because as Joseph Eagle Elk appropriately stated, this author group could not have produced this essential handbook on important topics in indigenous health research without each other.

The supplemental issue's topics and themes represent a comprehensive array of fundamental considerations for the ethical and principled conduct of health-related research with indigenous communities. In many ways, the work described grapples with issues presented in the field-based research literature with indigenous populations almost 50 years ago. For this reason, I will include concepts from a number of these classic citations that, while too often neglected at the time of their publication, remain highly relevant today and demonstrate these are not new considerations in which the IRINAH projects are making promising inroads, but instead represent a long historical arc of thinking in research conduct. On this point, in their summary article to the supplemental issue, Rasmus, Whitesell, Mousseau, and Allen (2019) emphasize 
that the "themes collectively inform an ethical and rigorous Indigenous intervention science. Collectively, they suggest a roadmap for advancing Indigenous perspectives and self- determination in health intervention research." (p. 1)

The array of considerations contained represents a challenging agenda. Some of the themes that stand out center on the challenges of using small samples, cultural measurement equivalence, translation and dissemination of evidence-based interventions, infusing culturally based life ways and folkways into all aspects of the research process and maintaining rigorous research standards ever mindful of the culturally sensitive ethnical responsibilities of conducting research with ethnocultural populations. The reader of this supplemental issue is often challenged to set aside conventional research paradigms to comprehend sometimes vastly different worldviews and through this process is introduced to profound insights, engaging observations, and important research results, along with cutting-edge commentary on the future of healthcentered research and practice with indigenous populations.

In reflecting on the general intent of the supplemental issue, two additional themes emerge for consideration. First, further attention should be devoted to the degree and depth of the cultural competence and sensitivity of field-based research teams and on methods for trust and relationship development. Second, by extension, careful consideration should be given to culture and leadership style.

My intent is not to overlook or in any way diminish the important contributions of the many indigenous (and nonindigenous) scholars reflected in the IRINAH supplemental issue, nor the research relationships they had built with indigenous community partners prior to IRINAH funding. However, based on 40 years of experience on $16 \mathrm{NIH}$ study sections, I believe there exist ongoing fundamental areas of cultural incongruity between many indigenous communities and research practice as supported by the institutes. Moreover, I note there are countless examples of Native people who have conducted research in Native communities and who are no longer welcomed in those communities. Though there has been significant progress, and the IRINAH initiative is representative of this progress, these two considerations provide areas for future progress. In effect, these considerations raise two important questions. Who will guide the community's policies, practices, and experiences of the research teams? Who will lead the funding and policy sources and the next generation of researchers?

\section{Who Will Guide the Community Direction of Research: a Relational Methodology}

As Crump et al. (2019) and Whitesell et al. (2019) note in the opening two articles of this issue, the presence of researchers in ethnocultural communities, especially North America indigenous communities, is cause for considerable concern, suspicion, and mistrust among many community members. Even the mere suggestion that one is an academic is enough to spark controversy. Often, this is even the case for researchers who share the same ethnicity as members of the host community.

Stanley et al. (2019) emphasize the critical importance of addressing mistrust and these concerns, given the magnitude of health inequities faced by indigenous communities. The origins of suspicion derive from two primary sources: a community's lack of experience with the research process, and past negative relationships with previous researchers.

In response, the RFA for the IRINAH program required an indigenous member of the investigator team, previous indigenous research experience by the team, and evidence of strong tribal or community support. These requirements are evidence of significant progress over the past 50 years. I share additional thoughts on why this issue IRINAH project is all currently navigating matters so deeply, in order to suggest avenues for additional progress.

Access to indigenous populations is becoming more and more difficult and demanding; some would argue it always has been difficult and demanding. As evident in description of the work in the supplemental issue (Gittelsohn et al. 2019), researchers should be prepared to collaborate with communities, share results that have practical value, and accept the conditions imposed by the community in gaining access to information and respondents. I have termed these and additional considerations elsewhere as elements of a relational methodology (Trimble and Fisher 2005; Trimble and Mohatt 2005), and I would like to argue here that there is critical need for further development of its theory and praxis on a level of similar priority afforded that of mainstream areas of methodology such as experimental design and analytic design.

In conducting culturally distinct research with indigenous populations, the would-be researcher sets a process in motion that, of necessity, must take into consideration both the ethos (the emotional communality) and eidos (the cognitive communality) of the groups in question. Not to do so could lead to an early death of the project and likely alienate the research team from future work with the community. When this happens, community members receive further substantiation for their levels of distrust toward research and its progenitors. Lack of cultural sensitivity and awareness of community dynamics sets up a difficult situation. Science receives a bad reputation (often much deserved), while the community problem continues to go unsolved.

Anyone who has conducted participatory communitybased fieldwork knows the work is tough and sometimes dangerous for everyone involved. To gather information necessary to frame a culturally specific perspective incorporating life ways and thoughtways requires extraordinary patience 
and perseverance, tempered with well-developed value orientations and research skills.

The esteemed cultural anthropologist, Mead (1977), reminds us:

The ethnologist [field-based researcher] cannot march upon a native community like an invading army, for that community is going to be not only a source of labor and food, but also the very stuff of his [sic] investigation. He must slip in quietly, lower himself or herself as gently as possible into the placid waters of native life, make the unprecedented arrival of an inquiring white person [or similarly, any person from outside the community] as inconspicuous as possible... (Howard 1984, p. 117)

And, then as Mead suggests in another source, "the way to do fieldwork is never to come up for air until it is all over." (Mead 1977, p. 136).

Many indigenous communities have limited experience and little or no understanding or appreciation for academicgrounded research. Scientism, the ideology that promotes science as the only objective means by which society should determine its values, and all its trimmings often are foreign to the residents. Researchers often are viewed by community residents as socially and culturally marginal to the society they intend to study. Consequently,

no matter how skilled he [sic] is in the native tongue, how nimble in handling strange social relationships, how artistic in performing social and religious rituals, and how attached he is to local beliefs, goals, and values, [the researcher] rarely deludes himself to thinking that many community members really regard him as one of them. (Freilich 1970, p. 2; see Tierney 2001)

An intense concern about all research is emerging among many people from different ethnocultural communities, and community members are becoming increasingly vocal about the problems many researchers create for them. In particular, communities are becoming concerned about the presence of "outside" researchers, by which they often mean individuals not current living in their community; many are intolerant and unforgiving of past research efforts. While the once popular and widely used "safari-scholar" approach to research is now fading from acceptance and "one-stop data mining" by itinerant researchers is no longer acceptable, more than ever, indigenous communities are demanding that research in their communities occurs under their direction and control.

One mechanism of control and direction has involved tribal or community review of research projects. Gittelsohn et al. (2019) notes tremendous variation in current approval processes for research in indigenous communities and additionally highlights specific variation that accompanies the unique challenges in garnering approval within urban indigenous contexts. While acknowledging this significant variation, in most Native American Indian, Alaska Native, and Native Hawaiian communities in the USA, there is now recognized requirement acknowledged by the research community that all researchers need to obtain some form of community review and oversight. Often in these review processes, researchers conducting research in a tribal nation will present a prospectus to the tribal council, or its designate, for review and sanction. Off of lands with tribal jurisdiction, this may instead take the form of some other respected organization or a research steering committee locally acknowledged to represent the community. If sanctioned, researchers are granted, either formally or informally, what is equivalent to a solicitor's license. Typically, this approval carries with it a number of contingencies and researcher responsibilities, which may include (a) assignment of a knowledgeable tribal or village member to monitor all research activities; (b) restrictions on the nature and composition of potential respondents (such restriction can make random sampling and assignment to intervention almost an impossibility); (c) right to review all original and completed research questionnaires, interview schedules, and field notes; (d) right to review any documents submitted for publication, with the understanding that the tribe or community has the right to reject publication of such documents and/ or certain interpretations of the data within them; and (e) right to review, comment, and pass judgment on final approval of any final reports. Add to these contingencies the procedures for development of research and intervention protocols, and for obtaining true informed consent from intervention research participants and protecting their rights as required by university IRBs, and one could readily surmise that conducting intervention science in these settings is much more complex than randomly pooling college students to test an intervention in quasi-laboratory settings, or simple adaptation of an existing intervention (Ivanich et al. 2019).

Gaining entry into the field, once achieved, carries an enormous responsibility that defines relational methodology. Responsibility extends both to the community and to maintenance of the researcher's own scientific integrity. However, most importantly, the researcher should recognize that mistakes, errors in protocol, and violations of cultural norms, beliefs, and values are not easily forgiven by members of the host communities. Dickerson et al. (2019) provide description of why past practice of impetuously and boldly rushing into a community for the sheer sake of advancing one's pet theory and hopefully promoting science in the process is unconscionable, intolerable, and indeed disrespectful.

Before setting foot into a culturally different community for the purposes of conducting research, researchers would do well to heed the seminal and still relevant recommendations of those who have been there before. After spending some 5 years conducting research on the aging process in 
numerous ethnic minority communities in the USA, Bengsten et al. (1977) drew up the following considerations for researchers:

- Research should be multidisciplinary. If not possible, the solitary researcher should seek the consultation of other social and behavioral scientists and persons who have some working knowledge of the community in question.

- Conventional laboratory grounded research strategies are not easily translated to field research. The scientific community will be concerned with methodological soundness and the lay community will want to be assured that they are not getting ripped off, that their collective voices will be heard, and that they will share in monetary remuneration if it is available.

- Because of the number of the community members involved, the potential for conflict between the lay community and professional researchers is considerable and may demand that strategies for conflict resolution be given consideration equal to that directed toward design criteria and methodological procedures.

- Above all the considerations, field researchers must be prepared to adapt to many changes that could occur in the course of the effort. They must be prepared to revise strategies and tactics to accommodate the changing concerns of community life.

While there is a great deal of disagreement about definitions of multicultural competency and cultural competence, there is much more agreement about recognizing instances of multicultural incompetence (Danso 2018). The fallout and untoward consequences of cultural incompetence are unprecedented in the annals of the history of humanity; the emotional, psychological, physical, ecological, medical, and economic costs are extraordinary and often beyond comprehension. Further efforts in formally and informally encouraging cultural competency in every aspect of projects can reduce the costs of multicultural incompetence. These considerations associated with competence extend to culture and leadership.

\section{Who Will Lead the Research Team: Culture and Leadership Style}

Past experiences have demonstrated that success and failure for those who embark on research with indigenous populations hinge on several preliminary steps. In their seminal work with a Navajo community, Adair and Deuschle (1970) recommended:

1). Those members of the donor society concerned with planned change must have a comprehensive knowledge of the culture of those for whom the innovations are designed. 2). In addition, there must be constant awareness on the part of those planning change of their own culture (or subculture), its values, structures, traditions, and biases. And 3). The political structure . . .must be understood and its leadership identified and worked through. (pp. xiv-xv)

In describing his leadership style, not long ago, a village elder and leader from an Alaska Native community stated it as, "being grounded in the ancestors and looking forward..." In many ways, his description fits the generally accepted definition and purpose of leadership. In essence, the general purpose of leadership includes creating a supportive environment where people can thrive, grow, and live in peace with one another, promote harmony with nature, and thereby provide sustainability for future generations by creating communities of reciprocal care and shared responsibility - communities where every person matters, each person's welfare and dignity is respected and supported, and a valuing of difference framework promotes inclusiveness (Trimble et al. 2012).

I wish to emphasize again at this point the tremendous cultural diversity within the imposed ethnic category of American Indian, Alaska Native, and Native Hawaiian (Trimble and Bhadra 2014). I do not wish to be misunderstood as suggesting here that one model of leadership applies to such diverse communities. More importantly, Warner and Grint (2006) point out that, "indigenous leadership styles encompassed a continuum of styles that defy any simple reduction" (p. 232). I am arguing instead there exist some common core elements of traditional leadership styles that do apply to many (but certainly not all) indigenous communities, in some element and through some variation. These core elements typical of leadership styles of many traditional indigenous people provide illustration of differences that existed with the conventional forms of leadership style that prevailed in the western world. Although we may never know how preEuropean contact traditional Indian leadership practices and styles actually played out, there is enough information available that enables us to list the essential and important elements (American Indian Research and Policy Institute 2005; Warner and Grint 2006). Additionally, I draw on Lakota leadership styles and prototypical elements as described extensively by Gambrell (2017) and Gambrell and Fritz (2011). The essential important point I wish to make here, through the following narrative description of one prototype for an Indigenous leadership style, is that there is in fact one model of leadership that is currently used by NIH for its grant awards, and this model is frequently in conflict or cultural incongruous with the many styles and variations of indigenous leadership models. Additionally, importance of culture and leadership style in culturally based intervention is profiled by Walters et al. (2018) and is implicated in the considerations of the critical 
importance of intervention sustainability in indigenous communities described by Jernigan et al. (2019b).

A core value across many indigenous leadership styles is a strong belief in connectedness; that is, everything is connected to everything else. A firm and unquestioned commitment to spirituality, the sacredness of all life, and respect for all that exists and existed sets in and around the leader. Traditionally, leaders did not view spirit and spirituality as objects to be set apart from life; they believed that spirituality and the sacred are inclusive of all that is and can be. Those who demonstrated strong leadership skills and talents usually were thought to have a stronger sense and respect for the spirit and the sacred.

In many of these systems, the selection or appointment of an indigenous leader was determined by the needs of the tribe and community. Selection was not necessarily based on popularity, but rather on the characteristics and traits of the individual and current perception of the problems or needs faced in which the person could assist in bringing about a solution. In essence, the ability to respond to a need or crisis determined the choice; hence, the decision was situation or context based. If the crisis or need was resolved, then another leader might be chosen to meet yet another circumstance of importance; one's term was not marked by a definitive period of time but rather on the degree to which a need was met or an obligation fulfilled.

With a very few exceptions, indigenous leaders of the past did not seek the distinction or appointment; they did not campaign or pursue community support. In some instances, leaders emerged because of their hereditary lineage; however, in some of those such instances, the leader was also reluctant to assume full and complete responsibility.

Leaders typically embraced strong positive values such as generosity, respectfulness, kindness, integrity, and trustworthiness. When leadership direction was requested of them, they acknowledged their responsibility to set a strong positive example for those to observe and follow. Firm values were essential in honoring the connectedness and relationships in the community.

Traditional leaders made it a point to engage the community in all discussions, and especially in ones requiring serious attention. Many leaders would spend their time visiting with families and elders. In effect, they saw their appointment as "a sphere of influence that must be contextualized" (Warner and Grint 2006, p. 231) rather than as a formal, coveted, delegated position. The role was primarily that of a facilitator and promoter of community values, traditions, beliefs, and interests (Badwound and Tierney 1988).

Gathering information from community members was a key element in reaching decisions, and in resolving conflicts and issues. Reaching those decisions was not always guided by fixed time constraints. Traditional leaders generally considered everyone's opinions, often gathered in collective settings where information gathering was group-centered rather than individual-centered. Decisions were not reached until all of the opinions and voices were heard. Traditional leaders placed a high premium on respect that carried over in the conduct of the discussion and deliberation process. The leader's goal was to achieve consensus; achieving that laudable goal was tedious and time consuming. The process represented the leader's deep respect for connectedness. In honoring the connectedness of all things, the leader recognized that a decision could never be ordered or imposed on the community. Decision and outcome were respected by the elders and community because all voices were thought to be heard, valued, and considered.

Achieving cultural competence in indigenous communities requires one to effectively collaborate with community leaders. While the core value of indigenous leadership styles often center on the principles of connectedness, leadership styles may vary considerably from one indigenous group to another. As emphasized earlier, the local political structure must be understood, and its leadership style identified and worked through.

Promoting and advocating for the principles of community-based participatory research, cultural competence, and the policies necessary for effective dissemination of health intervention and prevention research and practice (Jernigan et al. 2019b) requires a culturally competent leadership style at both the policy and research levels. Public policy initiatives reflect opportunities for sociocultural change and innovative forms of leadership where policy makers, community leaders, and researches forge alliances to respond to rapid sociocultural changes that promote organizational and institutional change. Research can advance effective leadership by embracing the principles of cultural competence in leadership styles and practices as they are occurring locally in the indigenous community context the project works within. As waves of new field-based researcher and policy analysts rise to levels of influence, careful attention and consideration must be given to engage the community in all discussions, especially on the issues that need serious attention. And above all else, as stated earlier and emphasized through the supplemental issue, as point of departure, researchers and policy makers should be prepared to collaborate with communities, share results that have practical value, and accept the conditions imposed by the community to gain access to information and participation.

\section{Relation in a Plane of Equality}

The Venezuelan community psychologist Montero (2004) talks about power, relationships, and differences when she emphasized:

Citizen participation means a horizontal, equal relationship. It means relating with the other at the same level. 
One understands one's usefulness as part of the solidarity produced within the relationship. Accepting the otherness involves admitting different modes of knowing and making possible the dialogue and the relation with the other in a plane of equality based on the acceptance of our own differences. (p. 251)

Power, relationships, and differences are intricately intertwined in the history and practice of research with ethnocultural communities. The authors of the articles in this supplemental issue advocate for a field-based intervention science in which researchers establish community relationships built on trust and respect for different life ways and thoughtways.

Montero's clarion call to researchers comes none too soon, as community voices challenge the way research historically has been conducted and the way participants were treated during the research process. Her call also captures an important broader shift in approach within intervention science that is alluded to throughout the supplemental issue, increasingly aligned with viewpoints of indigenous psychologies (Smith 1999) and emerging community intervention paradigms (Jernigan et al. 2019a; Trickett et al. 2011).

\section{Compliance with Ethical Standards}

Conflict of Interest The author declares that he has no conflict of interest.

Ethical Approval This article does not contain any studies with human participants or animals performed by any of the authors.

Informed Consent Because this article is a commentary informed consent is not applicable.

\section{References}

Adair, J., \& Deuschle, K. W. (1970). The people's health: Anthropology and medicine in a Navajo community. New York: Appleton Century-Crofts.

American Indian Research and Policy Institute. (2005). Traditional American Indian leadership. In A report prepared for the American Indian Research and policy institute. St. Paul: Author.

Badwound, E., \& Tierney, W. G. (1988). Leadership and American Indian values: The tribal college dilemma. Journal of American Indian Education, 28, 9-15.

Bengsten, V., Grigsby, E., Corry, E., \& Hruby, M. (1977). Relating academic research to community concerns: A case in collaborative effort. Journal of Social Issues, 33, 75-92.

Crump, A. D., Etz, K., Arroyo, J. A., Hemberger, N., \& Srinivasan, S. (2019). Accelerating and strengthening Native American health research through a collaborative NIH initiative. Prevention Science. https://doi.org/10.1007/s11121-017-0854-5.

Danso, R. (2018). Cultural competence and cultural humility: A critical reflection on key cultural diversity concepts. Journal of Social Work, 18, 410-430. https://doi.org/10.1177/1468017316654341.
Dickerson, D., Baldwin, J. A., Belcourt, A., Belone, L., Gittelsohn, J., Kaholokula, K., Lowe, J., Patten, C. A., \& Wallerstein, N. (2019). Encompassing cultural contexts within scientific research methodologies in the development of health promotion interventions. Prevention Science. https://doi.org/10.1007/s11121-018-0926-1.

Freilich, M. (Ed.). (1970). Marginal natives: Anthropologists at work. New York: Harper \& Row.

Gambrell, K. M. (2017). The case for an indigenous collectivist mindset. In J. L. Chin, J. E. Trimble, \& J. E. Garcia (Eds.), The culturally diverse leader: New Dimensions, opportunities and challenges for business and society (pp. 21-39). Bingley: Emerald Group Publishing Limited.

Gambrell, K. M., \& Fritz, S. M. (2011). Healers and helpers, unifying the people. A qualitative study of Lakota leadership. Journal of Leadership and Organizational Studies, 19, 315-325.

Gittelsohn, J., Belcourt, A., Magarati, M., Booth-LaForce, C., Duran, B., Mishra, S. I., Belone, L., \& Jernigan, V. B. B. (2019). Building capacity for productive indigenous community- university partnerships. Prevention Science. https://doi.org/10.1007/s11121-0180949-7.

Howard, J. (1984). Margaret Mead: A life. New York: Simon and Schuster.

Ivanich, J., Mousseau, A. C., Walls, M., Whitbeck, L., \& Whitesell, N. R. (2019). Pathways of adaptation: Two case studies with one evidence-based substance use prevention program tailored for indigenous youth. Prevention Science. https://doi.org/10.1007/s11121018-0914-5.

Jernigan, V. B. B., D'Amico, E. J., Duran, B., \& Buchwald, D. (2019a). Multilevel and community-level interventions with Native Americans: Challenges and opportunities. Prevention Science. https://doi.org/10.1007/s11121-018-0916-3.

Jernigan, V. B. B., D’Amico, E. J., \& Kaholokula, J. K. (2019b). Prevention research with indigenous communities to expedite dissemination and implementation efforts. Prevention Science. https:// doi.org/10.1007/s11121-018-0951-0.

Mead, M. (1977). Letters from the field, 1925-1975. New York: Harper.

Montero, M. (2004). New horizons for knowledge: The influence of citizen participation. In L. Jason, C. Keys, Y. Suarez-Balcazar, \& M. Davis (Eds.), Participatory community. research: Theories and methods in action (pp. 251-261). Washington, DC: American Psychological Association.

Rasmus, S.M., Whitesell, N.R., Mousseau, A. et al. Prevention Science (2019). https://doi.org/10.1007/s11121-019-01025-1

Smith, L. T. (1999). Decolonizing methodologies: Research and indigenous peoples. London; New York; Dunedin, N.Z.; New York: University of Otago Press; Distributed in the USA exclusively by St. Martin's Press.

Stanley, L. R., Swaim, R., Kaholokula, J. K., Kelly, K. J., Belcourt, A., \& Allen, J. (2019). The imperative for research to promote health equity in Indigenous communities. Prevention Science. https://doi.org/ 10.1007/s11121-017-0850-9.

Tierney, P. (2001). Darkness in El Dorado: How scientists and journalists devastated the Amazon. New York: Norton.

Trickett, E. J., Beehler, S., Deutsch, C., Green, L. W., Hawe, P., McLeroy, K., Miller, R. L., Rapkin, B. D., Schensul, J. J., Schulz, A. J., \& Trimble, J. E. (2011). Advancing the science of community-level interventions. American Journal of Public Health, 101, 1410-1419.

Trimble, J. E., \& Bhadra, N. (2014). Ethnic gloss. In K. Keith (Ed.), Encyclopedia of cross- cultural psychology (pp. 500-502). New York: Wiley.

Trimble, J. E., \& Fisher, C. (2005). Handbook of ethical considerations in conducting research with ethnocultural populations and communities. Thousand Oaks: Sage.

Trimble, J. E., \& Mohatt, G. V. (2005). Coda: The virtuous and responsible researcher in another culture. In J. E. Trimble \& C. B. Fisher (Eds.), Handbook of ethical and responsible research with 
ethnocultural populations and communities (pp. 325-334). Thousand Oaks: Sage.

Trimble, J. E., Rivkin, I. D., Johnson, S., Lopez, D. S., Orr, E., Allen, J., Fok, C., \& Henry, D. B. (2012). 'Taringenqegcallrat cayarat umyuatllu': Indigenous understandings in community based participatory research. Symposium published online by invitation in SCRA special issue of the Global Journal of Community Psychology Practice, 2(3).

Walters, K. L., Johnson-Jennings, M., Stroud, S., Rasmus, S., Charles, B., John, S., Allen, J., Kaholokula, J. K., Look, M. A., de Silva, M., Lowe, J., Baldwin, J. A., Lawrence, G., Brooks, J., Noonan, C. W., Belcourt, A., Quintana, E., Semmens, E. O., \& Boulafentis, J. (2018). Growing from our roots: Strategies for developing culturally grounded health promotion interventions in American Indian, Alaska Native, and Native Hawaiian communities. Prevention Science. https://doi.org/10.1007/s11121-018-0952-z.

Warner, L. S., \& Grint, K. (2006). American Indian ways of leading and knowing. Leadership, 2, 225-244.

Whitesell, N. R., Mousseau, A., Parker, M., Rasmus, S., \& Allen, J. (2019). Promising practices for promoting health equity through rigorous intervention science with indigenous communities. Prevention Science. https://doi.org/10.1007/s11121-018-0954-x.

Publisher's Note Springer Nature remains neutral with regard to jurisdictional claims in published maps and institutional affiliations. 